\title{
Assessing Quality of Care in Pharmacy: Remembering Donabedian
}

\author{
Michael T. Rupp, PhD, BSPharm, FAPhA
}

\begin{abstract}
SUMMARY
While some incremental and fragmented progress has been made in recent years, assessing the quality of care provided by pharmacists and pharmacy organizations remains an elusive goal. Revisiting the simple, elegant model of quality assessment originally proposed by physician and scholar Avedis Donabedian can assist pharmacy quality managers to develop a more comprehensive approach to measuring, monitoring, and managing the quality of care.
\end{abstract}

J Manag Care Spec Pharm. 2018;24(4):354-56

Copyright $\odot 2018$, Academy of Managed Care Pharmacy. All rights reserved.

I $\mathrm{t}$ has been more than a decade since the Pharmacy Quality Alliance (www.pqaalliance.org) was established, and I remain an enthusiastic advocate of the organization's mission to create and disseminate metrics with which the quality of care in pharmacy may be measured and compared. At the same time, I confess to being discouraged by a continuing emphasis on metrics that, while not irrelevant to quality, do not seem to address the most crucial aspects of pharmaceutical care that is delivered to patients by pharmacists and pharmacy organizations.

I think part of the problem is a misunderstanding-or at least a different understanding - of how quality is defined as it relates to pharmaceutical care, and how this elusive construct is best measured. It occurs to me that a better understanding of these diverging viewpoints would be helped by a bit of historical perspective.

\section{Quality Assessment Origins}

Perhaps the most seminal conceptual advances to assessing quality in health care were made by physician and scholar Avedis Donabedian (1919-2000) upon whose shoulders much of our current understanding has been built. While still a young faculty member, I was privileged to spend several days as Donabedian's escort during a series of lectures he presented at Purdue University in 1990. Having studied his work extensively during graduate school, I will admit to having been completely star struck at the prospect of spending quality time (no pun intended) alone with such an eminent scholar. Indeed, his impressive intellect and gentle wit did not disappoint. However, I was surprised by the genuine compassion and humility of the man and the depth of his commitment to improving the quality of health care.

Donabedian is probably best known for his tripartite approach to the assessment of health care quality, commonly known as the Structure $\rightarrow$ Process $\rightarrow$ Outcome model. ${ }^{1-3}$ But while this paradigm has been cited countless times by innumerable authors since it was originally advanced, it continues to be misunderstood, misrepresented, and misapplied, as Donabedian noted himself a number of times during our discussions. Because this confusion continues to represent a barrier to the assessment of quality in pharmacy and pharmaceutical care, I offer here a brief overview of Donabedian's conceptual model: "The Idiot's Guide to Donabedian," if you will. I think that would have made him laugh.

\section{Donabedian for Dummies}

Beginning with the seemingly self-evident observation that quality is a positive property of medical care that can and does vary, Donabedian explained that the degree of quality reflects "the extent to which the care provided is expected to achieve the most favorable balance of risks and benefits." Further, he observed, "I am reasonably certain that harm and benefits must be compared primarily as they are valued by the fully informed patient or his legitimate representative." ${ }^{\prime \prime}$

Thus, Donabedian explicitly recognized the relevance and, indeed, the primacy of the patient's perspective in quality assessment, at least insofar as determining the utilities for potential benefit and harm that may arise from health care. The now ubiquitous assessment of patient health-related quality of life is perhaps the single best contemporary expression of his patient-centric philosophy.

As the arrows imply, the Structure $\rightarrow$ Process $\rightarrow$ Outcome model suggests that a directional influence exists between 3 components of health care. It should be noted here that Donabedian did not suggest that structure, process, or outcome are themselves attributes of quality. Rather, he offered them as different approaches or perspectives that may be taken to acquire information about the presence or absence of the attributes that define quality.

According to Donabedian, "structure" refers to the context and environment of care, including factors of production such as the number and qualifications of providers, facility design, equipment, technology, and the manner in which health care services are organized and financed. "Process" refers to the interactions that occur between providers and patients, including, but not limited to, what providers do with, to, and for their patients. "Outcome" refers to a change in a patient's current and future health status that can be reliably attributed to antecedent health care.

Foremost among the triad-and a point of common misunderstanding of his model-is the process of care, which, as 
Donabedian suggested, represents the most direct and reliable approach to assessing quality. To the extent that the process of care was consistent with the norms for good medical care at the time it was provided, the quality criterion has been satisfied. Donabedian believed that to be true irrespective of, and even in spite of, the outcomes that may or may not have been achieved. That is, the proverbial operation really can be successful despite the death of a patient because negative outcomes may occur even in the presence of high quality care, a nuance commonly overlooked in health care assessment and medical malpractice lawsuits. Just because poor outcomes occurred in selected patients does not mean that poor care was provided. Similarly, positive outcomes do not necessarily imply good care, since some patients will improve despite the poor quality of care provided. The provision of high quality care merely increases the probability of positive outcomes and reduces the probability of negative outcomes-probabilities that require a representative population to properly express themselves.

Donabedian noted, however, that "while 'process' is the primary object of assessment, the basis for our judgment regarding quality is what is known about the relationship between the characteristics of the medical care process and their consequences to the health and welfare of individuals and of society." ${ }^{\prime \prime}$ Hence, it is our understanding of the relationship between the process of care and the achievement of desired outcomes and/or the avoidance of undesired outcomes that makes either relevant because "when the causal relationship between process and outcome is established, either can be used to make valid inferences about quality. When the causal relationship is not established, neither can be used."

Quality, Donabedian concluded, "is not represented by health status, but by the extent to which the improvements in health status that are possible are realized." That is, health care quality is defined not by a patient's ultimate health destination, but rather by the distance that was traversed in getting the patient to that destination. We would do well to remember this point when, for example, we attempt to compare Medicare star ratings for pharmacies that serve very different populations, in which the improvements that are realistically possible may differ markedly, a nuance that has only recently been recognized and has yet to be resolved. ${ }^{4}$

An alternative to process and, according to Donabedian, a decidedly less direct approach to assessing quality, is the evaluation of outcome, which he defined as a change in a patient's current and/or future health status that can be causally attributed to some antecedent health care event (i.e., process). Included under outcomes are physical and physiological changes, as well as social and psychological changes. This is in keeping with Donabedian's dual-domain definition of quality, which included technical and psychosocial aspects of care.

The final component in the tripartite paradigm is structure. Because the structural characteristics of care are most easily observed and measured, they were historically the most commonly used approaches to assessing quality. Donabedian challenged this perspective by suggesting that the structural components of health care are actually the most indirect and unreliable indicators of quality. Despite this limitation, however, he maintained that good structure in terms of the sufficiency of human and technical resources and proper system design is still an important means of protecting and promoting the quality of care. Adequate structure, therefore, is considered to be a necessary but insufficient determinant of quality, since adequate structure must be present, but structure alone is not enough to reliably ensure high quality care.

The functional relationship between the 3 components in Donabedian's model implies that the structural characteristics of the settings in which care takes place (e.g., the number and training of providers, facility design, and type and availability of equipment and technology) have a propensity to influence the process of care so that its quality is either diminished or enhanced. Likewise, the process of care, including variations in its delivery, will influence the consequences of care on health outcomes. Thus, Donabedian's model offers a simple, yet logical and systematic, way to approach the definition and measurement of quality in health care.

Although most of Donabedian's work focused on formal quality improvement activities within health care organizations, he recognized the importance of more subtle and informal mechanisms that also affect quality. Among these is the positive peer influence that providers can have on each other that results from "any activity that makes the work of practitioners visible to one another, to their students, and to other health care workers." He cautions, however, that such peer influence could also have a negative effect "in an institution where the prevalent norms are inimical to quality," in which case, "bad practice by some encourages bad practice by others."

\section{Take-Home Points}

So, where does all this leave us in assessing the quality of pharmaceutical care? First, quality lives in process-in what physicians, pharmacists, and others who are involved in the delivery of pharmaceutical care do with, to, and for patients, including patients themselves. The roles and responsibilities of each contributor to patient care must therefore be defined, and metrics must be created to determine the extent to which they have been fulfilled. What are the primary professional responsibilities of pharmacists relative to pharmaceutical care? What measures do we have of how consistently and how well these responsibilities are being accomplished?

Second, while the known structural prerequisites for quality must be maintained, we must recognize that the quality of care can be poor even if all the necessary structural elements are present. We should take care not to confuse necessary conditions for quality with sufficient conditions for quality. The former merely allow for high quality care to be delivered. The latter ensure it. 
Third, while the assessment of patient outcomes is an important component in the assessment of quality, there are some caveats that must be considered so that we do not place more weight on them than they are able to bear. One such caveat is that an intermediate outcome can only be reliably used as a proxy for an ultimate patient outcome if a strong relationship has been clearly demonstrated to exist between the two. For example, such a relationship has been clearly established between hemoglobin Alc and many of the ultimate patient outcomes we seek to affect in diabetes. In contrast, a much weaker relationship has been demonstrated between medication adherence and many of the ultimate patient outcomes we seek to improve via drug therapy, especially when our measures of adherence are merely inferred from claims data, and the values we have established for what constitutes acceptable adherence is largely arbitrary (e.g., 80\% proportion of days covered).

Finally, even if patient medication adherence could be accurately measured and valid targets established, the degree to which it is indicative of the quality of care provided by the pharmacist or pharmacy organization is questionable. The use of medication adherence metrics that are contained in Medicare star ratings to infer the quality of care provided by pharmacists in reporting pharmacies is a case in point. Can pharmacists have some influence on these voluntary decisions by patients? Yes, I will concede they can. But is medication adherence a legitimate measure of the relative quality of care provided by pharmacists? That is disputable and, indeed, has been disputed. ${ }^{6}$ Moreover, even if medication adherence is a legitimate measure of the quality of pharmacist care, it does not rise to the same level of importance as prospective drug utilization reviews, accurate prescription dispensing, or high quality patient counseling, none of which are routinely measured now in a reliable way.

It would appear, then, that we still have a way to go before we are able to legitimately measure, compare, and contrast the quality of care delivered from different pharmacies or by different pharmacists, given the current state of the science and art of quality assessment.

\section{Conclusions}

Donabedian will be rightly remembered and revered for his seminal contributions to developing a truly systematic approach to quality improvement in health care. However, to those who had the pleasure of knowing him, a glimpse into the "secret sauce" that made him the remarkable person he was can be found in the final paragraphs of the book he completed shortly before his death, a death he clearly saw coming:

Often I have cast the commitment to quality in moral terms, preferring to see it as the ethical imperative that must govern the conduct of all caregivers. More recently, as I contemplate the imminent end of my every activity, a religious, a transcendent element has crept into my thinking. The secret of quality, I wish to believe, is love: love of one's profession, love of one's fellow man, and love of God. ... I cannot, of course, impose any of my own feelings and beliefs upon the reader. I can only hope that each reader of these pages will extract from them what seems most pertinent and useful and, perhaps, go away strengthened and inspired. ${ }^{5}$

Donabedian called it love. Others may refer to it as compassion, consideration, or simply caring. Whatever you call it, he believed it was the secret ingredient of quality. I wonder if some of the work currently being done in quality assessment and continuous quality improvement would not be improved by trying to measure that special ingredient in the care provided by pharmacists and pharmacy organizations.

\section{Authors}

MICHAEL T. RUPP, PhD, BSPharm, FAPhA, Midwestern University College of Pharmacy, Glendale, Arizona.

AUTHOR CORRESPONDENCE: Michael T. Rupp, PhD, BSPharm, FAPhA, Midwestern University College of Pharmacy, 19555 N. 59th Ave., Glendale, AZ 85308. Tel.: 623.572.3528; E-mail: mtrupp@midwestern.edu.

\section{DISCLOSURES}

No funding supported the writing of this article. The author has no relevant conflicts of interest to disclose.

\section{REFERENCES}

1. Donabedian A. Explorations in Quality Assessment and Monitoring. Vol 1: The Definition of Quality and Approaches to Its Assessment. Ann Arbor, MI: Health Administration Press; 1980:5, 10, 27, 79, 113.

2. Donabedian A. Explorations in Quality Assessment and Monitoring. Vol. 2: The Criteria and Standards of Quality. Ann Arbor, MI: Health Administration Press; 1982.

3. Donabedian A. Explorations in Quality Assessment and Monitoring. Vol. 3: The Methods and Findings of Quality Assessment and Monitoring: An Illustrated Analysis. Ann Arbor, MI: Health Administration Press; 1985.

4. Desai V, Nau D, Conklin M, Heaton PC. Impact of environmental factors on differences in quality of mediation use: an insight for the Medicare star rating system. J Manag Care Spec Pharm. 2016;22(7):779-86. Available at: https://www.jmcp.org/doi/10.18553/jmcp.2016.22.7.779.

5. Donabedian A. An Introduction to Quality Assurance in Health Care. New York: Oxford University Press; 2003:xxix, 138.

6. Sorensen TD, Pestka DL, Brummel AR, Rehrauer DJ, Ekstrand MJ. Seeing the forest through the trees: improving adherence alone will not optimize medication use. J Manag Care Spec Pharm. 2016;22(5):598-604. Available at: https://www.jmcp.org/doi/10.18553/jmcp.2016.22.5.598. 